\title{
Assessing branch efficiency and managerial behaviour in a large Spanish commercial bank
}

\author{
Idaira Cabrera-Suárez* and Jorge V. Pérez-Rodríguez
}

Department of Quantitative Methods, University of Las Palmas de Gran Canaria, Las Palmas, Gran Canaria, Spain

\begin{abstract}
This paper describes a two-stage procedure used to evaluate determinants of operational efficiency and profit dimensions, as an indication of the performance of branch managers in a large Spanish commercial bank, before and after the bailout of the Spanish banking system in 2012. This procedure is based on both the non-parametric and robust non-parametric frontier methods and on partial frontier-based outlier detection (following Daraio and Simar) which enables us to detect potential outliers in the data, after which a classical non-parametric efficiency analysis is performed. In the first stage, efficiencies are obtained from annual data supplied by bank branches regarding the period 2011-2014. High scores were obtained in operational and profit efficiencies for DEA (pure technical and scale efficiencies), FDH and order-a estimators. In general, the following hierarchies of scores were obtained: $\mathrm{DEA}<\mathrm{FDH}<$ order-a. In the second stage of our analysis, a censored econometric model approach was applied (following Simar and Wilson) to identify the drivers of efficiency. Finally, the implications of this study for policymakers are discussed.
\end{abstract}

\section{Evaluación de la eficiencia de las sucursales y el com- portamiento gerencial en un gran banco comercial español}

\section{RESUMEN}

Este documento describe un procedimiento de dos etapas para evaluar los determinantes de la eficiencia en las dimensiones operativa y de beneficios en un gran banco comercial español, como indicadores del nivel de desempeño de los gerentes de las sucursales antes y después del rescate del Sistema Bancario español en 2012. Este procedimiento se basa en métodos de frontera no-paramétricos y noparamétricos robustos, y en el método basado en la detección de outliers en fronteras parciales siguiendo a Daraio y Simar, lo que nos permite detectar valores atípicos potenciales en los datos, y después realizar un análisis clásico de eficiencia no paramétrica. En la primera etapa, las eficiencias se obtienen a partir de los datos anuales de las sucursales bancarias en el periodo 2011-2014. Los resultados indican que las puntuaciones de eficiencia operativas y de ganancias son elevadas para DEA (eficiencia técnica pura y de escala), FDH y order$a$; obteniéndose la jerarquía siguiente: $\mathrm{DEA}<\mathrm{FDH}<$ order-a. En la

\section{ARTICLE HISTORY}

Received 20 May 2017

Accepted 3 December 2018

\section{KEYWORDS}

Bank branches; technical and scale efficiencies; DEA; FDH; Order- $\alpha$; Simar-Wilson procedure

JEL CLASSIFICATION C02; C44; C61; D24 
segunda etapa de nuestro análisis, se aplicó un modelo econométrico censurado siguiendo el procedimiento de Simar y Wilson para identificar los factores explicativos de la ineficiencia. Finalmente, se discuten las implicaciones de este estudio.

\section{Introduction}

Many studies have analysed bank efficiency in Spain, focusing on commercial banks, savings banks and credit unions, among other areas. In general, the methods applied in this prior research are based on non-parametric procedures such as data envelopment analysis (DEA) and free disposal hull (FDH, a non-convex variant of DEA). However, parametric stochastic procedures such as stochastic frontier analysis (SFA) have also been used. ${ }^{1}$ Among the non-parametric methods, most studies have used the DEA framework to estimate bank efficiency, see, for example, Pastor (1995), Grifell and Lovell (1997), Pastor, Pérez, and Quesada (1997), Maudos, Pastor, and Pérez (2002), Cuesta and Orea (2002), Maudos and Pastor (2003), Guzmán and Reverte (2008), Färe, Grosskopf, Maudos, and Tortosa-Ausina (2010) and San-José et al. (2014). In this respect, too, Prior, TortosaAusina, García-Alcober, and Illueca (2016) performed an efficiency analysis for Spanish banking, using the FDH approach to address the periods before and during the recent international economic crisis. ${ }^{2}$ In an alternative approach, SFA has been used in some studies, such as Maudos (1996), Maudos (2001), Maudos and Pastor (2001a, 2001b)) and Orea and Kumbhakar (2004). Finally, Weill (2004) applied and compared the DEA, FDH and SFA techniques in an analysis of the banking industry in several countries, including Spain.

Analyses at the bank branch level are often more useful than those at the institutional level, both for academic researchers and for within-bank staff. The branch data for a single bank are collected in a uniform and comparable manner, and therefore do not create serious problems for the interpretation of scale efficiency. Moreover, branch homogeneity is a basic requirement of DEA in order to minimise estimation bias (Chortareas, Girardone, \& Ventouri, 2009; Coelli, Prasada Rao, O’ Donnell, \& Battese, 2005). Berger, Leusner, and Mingo (1997) indicated that information on branch performance may help improve our understanding of bank efficiency and contribute to resolving measurement problems in this context. Therefore, the knowledge of efficiency allows branch managers to identify strengths and weaknesses in their operations and to minimise inefficiencies in bank operations, by highlighting deviations from a 'best practice' unit for any scale or product mix (Berger et al., 1997). In this respect, too, Paradi and Zhu (2013) indicated that the branch network is usually the largest source of operational expenses for a bank, and that customers perform a large proportion of their more value-added banking via branches. For example, even in digitally advanced European nations, between $30 \%$ and $60 \%$ of customers prefer doing at least some of their banking at branches. ${ }^{3}$

Our own analysis contributes to the empirical literature on bank branch efficiency in several ways. Firstly, we estimate technical efficiencies in a consistent fashion, in the view that non-parametric efficiency estimators are highly sensitive to the presence of outliers. To do this, we use the order- $\alpha$ non-parametric partial frontier method (Aragon, Daouia, \& 
Thomas-Agnan, 2005), which is more robust against measurement errors and outliers than traditional methods such as DEA or FDH. The order- $\alpha$ approach generalises FDH by allowing super-efficient observations to be located beyond the estimated productionpossibility frontier. Secondly, we identify problematic branches, taking into account that the estimated frontier will not be shaped entirely by abnormal observations. Hence, partial frontier analysis is performed to detect potential outliers in the data, after which DEA or FDH non-parametric efficiency analysis is applied (see Daraio \& Simar, 2007). This approach is an appropriate means of dealing with outliers, which might otherwise increase noise and distort results. Thirdly, we cross-check this robust non-parametric method against DEA and FDH, recalling that Krüger (2012) found DEA to be quite robust in Monte Carlo experiments designed to study non-parametric and parametric deterministic and stochastic methods. Finally, we evaluate the determinants of bank branch inefficiency, testing the relationship between estimated relative efficiency scores and environmental factors using Simar and Wilson's (2007) procedure. This method is preferred because conventional two-step approaches lack a well-defined data generating mechanism; for example, DEA generates a complex (unknown) pattern of correlation between the estimated efficiency scores.

Our analysis takes into account several environmental factors that may affect efficiency, a crucial metric for bank branch evaluation which could be related to the targets of the bank (Lovell \& Pastor, 1997). Therefore, we have focused on two metrics by the bank to evaluate its performance. On the other hand, we analyse the effects of branchspecific factors, such as market size (rural/urban) and the effect of experience (quantified as the number of years the branch has been in operation). This latter variable allows us to evaluate the learning curve and to determine the branch's ability to remain in the market (Bernini \& Guizzardi, 2010). Other variables considered are the quality of branch staff (in terms of financial quality certification), provisions for loan loss impairment, geographic location and branch specialisation. Furthermore, we take into account the effect of the Spanish banking crisis (and of the resulting bailout procedures) and of the regulatory reform conducted in 2012. In short, we analyse the performance (efficiency) of bank branches and their managers during a period in which financial institutions had to adapt to a new macroeconomic scenario, with regulatory changes, and in which a further recession hit the Spanish economy (in the first quarter of 2012), when a major restructuring of the banking industry took place.

The rest of this paper is structured as follows. The following section reviews the previous literature in this area. Section 3 then describes the use of DEA, FDH and partial frontier models to determine bank branch efficiency, taking into account different forms of returns to scale and restrictions on the models. We also describe the Simar and Wilson procedure. Section 4 presents the data obtained and the empirical results calculated. Finally, the main conclusions drawn are presented in Section 5.

\section{Literature review}

There is extensive literature on the efficiency of bank institutions as a whole (see Fethi and Pasiouras (2010), and references therein), and also on that of bank branches. In the latter respect, in particular, two surveys are outstanding: in the first, Fethi and Pasiouras (2010) discussed bank and branch efficiencies, analysing 30 studies, conducted between 
1998 and 2009, that used DEA techniques to estimate branch efficiency. Subsequently, Paradi and Zhu (2013) identified 80 studies in which DEA was applied to banks and their branches, over the period 1985-2011.

In the following, we briefly describe both non-parametric and parametric stochastic approaches to study bank branch efficiency.

Firstly, regarding non-parametric methods, the most widely used method is DEA. Since Sherman and Gold (1985) wrote the first DEA application paper on bank branch analysis, several papers have proposed methodological improvements, such as including the value judgements of branch managers (Athanassopoulos, 1997), introducing fuzzy logic formulation (Wu, Yang, \& Liang, 2006), using multi-layer DEA (Alirezaee \& Afsharian, 2007) or a 'culturally adjusted' DEA model (Paradi, Vela, \& Zhu, 2010), evaluating branch performance for multi dimensions (Paradi, Rouatt, \& Zhu, 2011), and evaluating management efficiency and providing guidelines for improvements (Camanho \& Dyson, 1999: among others).

Many of the papers that analyse branches assume constant returns to scale, and radial efficiency measures are still the most widely used approaches. However, efficiency in operations is usually assessed in different areas or dimensions, because no single model can fully capture the multi-role nature of bank branches. Methods that have been adopted include the production approach (focusing on operational activity), the intermediation approach (concerning how efficiently the branch collects deposits and other funds) and the profitability approach (how well the branch generates profits). Service quality (or efficiency) is another significant dimension of bank branch performance. For each such dimension, there is significant diversity among previous studies in terms of the input/output selection made (see Table A1 in Paradi \& Zhu, 2013). DEA methods have been used to estimate technical and scale efficiencies, allocative and cost efficiencies and the evolution of bank branch productivity.

Technical efficiency has been analysed using one or several dimensions. With respect to a single dimension, Parkan (1987) examined the production efficiency of 35 branches of a major commercial bank in Canada and reported that only 11 were relatively efficient. Camanho and Dyson (2005b) analysed 144 branches of a Portuguese commercial bank and observed considerable inefficiencies in this network. Pastor et al. (2006) used DEA to examine the profit efficiency of 573 branch offices of a large European savings bank and reported that efficiency improvements at the worst-performing branches (where savings of up to $45 \%$ in the use of resources could be obtained), would generate a substantial increase in profit for the bank. Regarding several dimensions, Oral and Yolalan (1990) assessed the profit and service efficiencies of 20 retail branches of a Turkish commercial bank, finding a positive relationship between these parameters, but that only $20 \%$ of the branches were efficient. Portela and Thanassoulis (2007) used a post hoc analysis to compare service quality and different measures of efficiency, and reported that service quality was positively related with operational and profit efficiency. Giokas (2008a) assessed the production, transaction and profit efficiencies obtained in operations within a network of 44 branches during the financial year 2002. According to the empirical results obtained, there was scope for substantial improvements in efficiency (the average inefficiency was 12\%) and hence for increased bank profits. Paradi et al. (2011) analysed the three dimensions of branch performance related to technical efficiency for the 816 branches of a major Canadian bank, and concluded that these approaches enhanced the 
performance assessment method and enabled branch managers to clearly identify the strengths and weaknesses in their operations. Finally, Aggelopoulos, Georgopoulos, and Siriopoulos (2013) used production and profit dimensions to study Greek banks, considering the effects produced on bank branches before and during the crisis period.

DEA methods have also been used to evaluate the cost efficiency of bank branches. For example, Giokas (2008b), Camanho and Dyson (2005a, 2005b) and Tsolas and Giokas (2012), among others, have evaluated the ability of a branch to produce outputs at minimal costs, while Camanho and Dyson (2005a) estimated the upper and lower bounds of branch cost efficiency measures under diverse scenarios of price uncertainty.

Finally, DEA methods have been employed to evaluate productivity growth, according to the Malmquist index. Thus, Camanho and Dyson (2006) evaluated the performance of 144 Portuguese branches to determine the within-group efficiency spread, internal managerial efficiencies and frontier productivity, reflecting the impact of environmental factors and of regional managerial policies. In this respect, too, Asmild and Tam (2007) calculated frontier differences between bank branches in different countries.

Another non-parametric method, FDH, has been used to investigate bank branch efficiency, by Respaut (1989) and Tulkens (1993), while one of the few studies to consider productivity measures based on FDH was conducted by Tulkens and Malnero (1996).

On the other hand, parametric stochastic methods have rarely been applied to the analysis of bank branch efficiency. To our knowledge, only stochastic cost frontier (SCF) models and panel data frameworks have been employed, for example, by Berger et al. (1997) for US banks, by Osiewalski and Marzec (1998) and Marzec and Osiewalski (2008) for Polish banks in a Bayesian context, and most recently, by Cabrera-Suárez and Pérez-Rodríguez (2017) for a large Spanish commercial bank. The latter authors proposed the joint analysis of time-varying cost efficiencies and unobserved heterogeneity within bank branches.

The majority of the above studies have analysed efficiency but not its determinants. To evaluate the effects of certain environmental variables on efficiency in a non-parametric setting, empirical studies usually adopt a two-stage approach. First, a DEA with inputs and outputs is performed, after which efficiency scores are regressed against environmental variables. Several studies have investigated the factors that influence the efficiency of bank branches. In their review, Paradi and Zhu (2013, p. 65) classified these studies into the following categories: cross-country branch comparison, cross-bank comparison, crossregion branch comparison and analysis of the impact of some exogenous factors, such as technology innovations. ${ }^{5}$ For example, the effects produced on branch efficiency by differences in regional characteristics have been analysed by Das, Ray, and Nag (2009) and Deville (2009). In the first of these studies, the branch-level labour-use inefficiency of a single bank was measured, in four major cities in India. Regarding the effect of technological innovation, Cook, Seiford, and Zhu (2004) analysed the effect of e-business activities on banking performance. In another approach, Fethi and Paisouras (2010) considered the diversity of environments in which the branches are operating, while Paradi and Schaffnit (2004) examined the role of the environmental parameters that are beyond management control, with respect to the commercial branches of a large Canadian bank, and incorporated the risk and economic growth rate of the region as non-discretionary factors.

In Spain, few studies have been conducted of the efficiency of retail branch networks, whether employing DEA or other non-parametric methods. In fact, to the best of our 
knowledge, there has only been the paper by Lovell and Pastor (1997), cited in the introduction. These authors used a DEA framework and variable returns to scale, with a single constant input, or equivalently, with no inputs. The problem addressed in this case was to maximise the radial expansion on the vector of 17 success indicators for the 545 bank branches evaluated.

In summary, current empirical evidence on the various dimensions of branch efficiency indicates that non-parametric DEA is the most commonly used approach, and that little research has been undertaken to analyse branch efficiency in the Spanish bank system. Therefore, our study of efficiency is well-suited to provide an empirical illustration of the effects of environmental factors on branch efficiency scores, using both nonparametric and robust non-parametric methods.

\section{Classical and robust non-parametric estimators}

In this study, both non-parametric and robust non-parametric approaches for frontier estimation are employed, specifically, non-parametric DEA and FDH, together with the non-parametric order- $a$ estimator, which is more robust to the existence of outliers. In addition, input-oriented models are constructed because the amount of business available to a branch depends largely on customer demand for the bank's services and is beyond the branch manager's control (Paradi et al., 2011). ${ }^{6}$

Let $n$ be observations of bank branches (or, in general, decision-making units, DMUs), $j=1,2, \ldots n$. Let $x_{i j}$ be the observed level of the $i$-th input at DMU $j$ and let $x_{j}=$ $\left(x_{1 j}, \ldots, x_{k j}\right) \in \Re_{+}^{k}$ be the vector of $k$ inputs for the $j$-th unit; $y_{r j}$ is the observed level of the $r$-th output at DMU $j$, where $y_{j}=\left(y_{1 j}, \ldots, y_{q j}\right) \in \Re_{+}^{q}$ is a vector of $q$ outputs.

\subsection{Full frontier functions estimated by non-parametric methods}

The main non-parametric estimators available are data envelopment analysis (DEA) and free disposal hull (FDH).

The DEA estimator of the production set, first proposed by Farrell (1957) and later operationalised as a linear programming estimator by Charnes et al. (1978, CCR model), assumes free disposability, the convexity of the production set and constant returns to scale (CRS). In the case of variable returns to scale (VRS; Banker, Charnes, \& Cooper, 1984; or BCC model), the estimated input DEA efficiency score for a branch operating at level $\left(x_{0}, y_{0}\right)$ is obtained by solving the following linear program (we omit subindices $i$ and $r$ for simplicity):

$$
\hat{\theta}_{j, D E A-V R S}\left(x_{0}, y_{0}\right)=\min \left\{\theta / y_{0} \leq \sum_{j=1}^{n} \lambda_{j} y_{j} ; \theta x_{0} \geq \sum_{j=1}^{n} \lambda_{j} x_{j} ; \sum_{j=1}^{n} \lambda_{j}=1 ; \lambda_{j} \geq 0 ; j=1, \ldots, n\right\}
$$

where $\lambda_{j}$ represents the optimal weights for unit $j, \hat{\theta}_{j, D E A-V R S}$ is between 0 and 1 , and $\hat{\theta}_{j, D E A-V R S}=1$ if the unit is fully efficient and $\hat{\theta}_{j, D E A-V R S}<1$ if it is inefficient.

The scale efficiency of bank branches can be calculated using the ratio of CCR technical efficiency (or global technical efficiency) to BCC technical efficiency (or pure technical efficiency), which identifies the proportion of inefficiency due exclusively 
to problems of size. However, a shortcoming of this measure of scale efficiency is that the value does not indicate whether the DMU is operating in an area of increasing or decreasing returns to scale. This question may be resolved by running an additional DEA problem with non-increasing returns to scale (NIRS) substituting the convexity restriction $\sum_{j=1}^{n} \lambda_{j}=1$ in the BCC model by $\sum_{j=1}^{n} \lambda_{j} \leq 1 .^{7}$

The FDH estimator, proposed by Deprins, Simar, and Tulkens (1984), is a more general version of the DEA estimator, which relies only on the free disposability assumption, and hence is not restricted to convex technologies. ${ }^{8}$

In practice, the FDH estimator is computed by a simple vector comparison procedure that amounts to a complete enumeration algorithm, as proposed in Tulkens (1993). Assuming input orientation, efficiency can be calculated by comparing each $\operatorname{DMU}(s=1, \ldots, n)$, and regarding all other DMUs $(j=1, \ldots, n)$ in the data that produce at least as much of any output as DMU s. The set of peer DMUs in the sample that satisfy the condition $y_{l j} \geq y_{l 0}, \forall l$ is denoted as $B_{j}$. Among the peer DMUs, the one that exhibits minimum input consumption serves as a reference to $s$, and the FDH estimator, $\hat{\theta}_{j, F D H} \leq 1$, is calculated as the relative input use, such that:

$$
\hat{\theta}_{j, F D H}\left(x_{0}, y_{0}\right)=\min _{j \in B_{j}}\left\{\max _{i=1, \ldots, k}\left(\frac{x_{i j}}{x_{0}}\right)\right\}
$$

This is a maximin procedure (for the 'input oriented' framework): the 'max' part of the algorithm identifies the most dominant DMUs relative to which a given DMU is evaluated. Once the most dominant DMUs are identified, slacks are calculated from the 'min' part of the algorithm.

\subsection{Partial frontier functions estimated by robust non-parametric methods}

One of the main drawbacks of frontier models (DEA/FDH based) is that they are highly sensitive to the existence of outliers and measurement errors (i.e. the influence of 'superefficient' outliers). This is a consequence of the fact that the efficient frontier is determined by sample observations which are extreme points. Simar (1996) pointed out the need to identify and eliminate outliers when using non-parametric models. If these outliers cannot be identified, then the use of stochastic frontier models is recommended.

As an alternative, studies have identified more robust methods based on nonparametric estimates of efficiency, such as partial frontier approaches.

The partial frontier envelops only a sub-sample of the data and is obtained from a probabilistic definition of the technology set. The order- $m$ (Cazals, Florens, \& Simar, 2002) and order- $\alpha$ (Aragon et al., 2005) approaches allow us to estimate the efficiencies of non-parametric stochastic partial frontiers.

Order- $m$ generalises FDH by adding a layer of randomness to the computation of efficiency scores. Rather than benchmarking a DMU by the best-performing peer in the sample at hand, order- $m$ is based on the idea of benchmarking the DMU by expected best performance in a sample of $m$ peers (see Daraio and Simar (2007) for the step procedure in computational terms). Order- $\alpha$ also generalises FDH but rather than using 
minimum input consumption among the available peers as a benchmark, it uses the $(100-\alpha)$ th percentile.

In this paper, we briefly comment on the order- $\alpha$ estimator, which is preferred because it does not require re-sampling, and thus is less time consuming than order-m.

The (100- $\alpha$ )th percentile with $0 \leq \alpha \leq 100$ can be calculated as

$$
\hat{\theta}_{j, \alpha}\left(x_{0}, y_{0}\right)=P_{\substack{100-\alpha \\ j \in B_{j}}}\left\{\max _{i=1, \ldots, k}\left(\frac{x_{i j}}{x_{0}}\right)\right\}
$$

The FDH model is a particular case of the order- $\alpha$ estimator when $\alpha=100$, enveloping all observations. When $\alpha<100$, some DMUs may be classified as super-efficient and are not enveloped by the estimated production-possibility frontier. $\alpha$ can be regarded as a tuning parameter that determines the number of super-efficient DMUs. In this case, $\hat{\theta}_{j, \alpha}>1$. Efficient units have $\hat{\theta}_{j, \alpha}=1$ and inefficient ones, $\hat{\theta}_{j, \alpha}<1$. The choice of $\alpha$ is usually within the interval $[90,99]{ }^{9}$

\subsubsection{Partial frontier-based outlier detection}

Partial frontier analysis can be used to detect potential outliers in the data, after which a non-parametric efficiency analysis by DEA or FDH could be performed (see Daraio \& Simar, 2007). For this analysis, points of discontinuity in the presence of outliers must be obtained. Thus, the DMUs classified as super-efficient for $\alpha \geq \alpha^{\text {disc }}$ (point of discontinuity) are the most likely outliers. These outliers can then be excluded from the efficiency analysis by applying FDH or DEA.

The approach suggested by Daraio and Simar (2007) has the following steps: (1) perform a series of partial frontier analyses for different values of $\alpha$; (2) plot the share of super-efficient DMUs against $\alpha$; (3) identify discontinuities in the resulting curve. These discontinuities reveal the outlier DMUs that are classified as super-efficient for the corresponding values of $\alpha$. Daraio and Simar (2007) suggested one global and two local rules for detecting discontinuities: (a) $\alpha$ for which the twice-differenced series has a minimum value (following a non-negative one); (b) values of $\alpha$ for which negative values persist after repeatedly smoothing twice-differenced series by running oddspaced median smoothers; and (c) $\alpha$ that minimises BIC in order to split the series into two parts and to fit a linear (quadratic) function to each one.

\subsubsection{Simar \& Wilson's procedure}

The effects of covariates (exogenous variables) on efficiency can be evaluated using a linear regression model, which is written as follows:

$$
\text { Efficiency } y_{j}=\beta^{\prime} z_{j}+e_{j}, j=1,2, \ldots, n
$$

where Efficiency $y_{j}$ is the efficiency score previously estimated; $z_{j}$ is a column vector of explanatory variables (including one for the constant term), $\beta^{\prime}$ is a row vector of unknown parameters to be estimated, and $e_{i}$ is an error term with standard deviation equal to $\sigma_{e}$.

$\beta^{\prime}$ and $\sigma_{e}$ were estimated by Simar and Wilson's (2007) procedure based on truncated regression using maximum likelihood (algorithm \#1, pages 41-42). This approach excludes the efficient DMUs and constructs models based on inefficiencies (values lower 
than 1). Our analysis is based on an input orientation, with right-truncation at 1 , as in Simar and Wilson's method. The following multi-step iterative procedure is performed: (1) truncated regression; (2) repeated sampling of pseudo-disturbances from the truncated normal distribution, generating artificial efficiency scores, and re-estimating the model; (3) calculation of simulated $\beta^{\prime}$ and $\sigma_{e}$ coefficient distributions.

\section{Empirical analysis}

\subsection{Data}

The empirical analysis presented in this paper is based on pure retail banking, which is a central element of the Spanish banking system.

Due to limited availability of data and difficulties arising from the banks' obligations of confidentiality, this study is focused on an anonymous large Spanish commercial bank, which operates via a regional network of bank offices. The bank in question is representative for our purposes, as one of the three largest banks in the country in terms of assets, given the high degree of concentration in domestic banking in this country. This bank was not affected by the bailout, ${ }^{10}$ although the macroeconomic scenario did slightly impair its internal labour productivity and operating efficiency. This favourable outcome may have been achieved because the bank has a diversified and balanced portfolio model, and because its management is based on prudence and anticipation.

Our study is based on annual data from the bank branches for the period 2011-2014, which included the second Spanish economic downturn (2011-2013) and the bailout of the Spanish banking system (2012) via the $€ 100$ billion rescue package provided by the European Stability Mechanism (ESM). In this period, the profitability of banks decreased and it was common practice for management to seek maximum efficiency in bank operations.

Annual accounting information was compiled from profit and loss statements, together with data from internal departments (such as management control and human resources), corresponding to 134 branches that managed both personal and business accounts, and provided similar services in each case (i.e. their activities were homogeneous). The branches were widely distributed across a given region in Spain, in rural and urban areas, some of which had a high concentration of branches. For reasons of confidentiality, no further identification is provided.

\subsubsection{Measuring the performance of branches: dimensions, inputs and outputs}

In this study, production and profit approaches were used to measure bank branch performance, in terms of increasing sales and managing the product mix to generate high profitability (Portela \& Thanassoulis, 2007). The nature and the quantity of inputoutput variables used in our assessment were selected after considering data availability.

In brief, the following production and profit approaches were employed.

The production approach emphasises operational activities; in other words, bank branches are viewed as providers of services to customers. In our analysis of these activities, the inputs used for each branch were the total number of full-equivalent employees (including branch and account managers, administrative and commercial 
staff and tellers), the number of external ATMs, the floor space (in $\mathrm{m}^{2}$ ) and the operational costs supported (total cost of materials, space and information systems, but excluding personnel costs). These inputs have also been used by Camanho and Dyson $(1999,2006))$. The outputs considered were the total value of loans (as mortgages and to consumer and business accounts) and the total value of savings (account deposits). These outputs, too, were used by Camanho and Dyson $(1999,2006)$ and also by Giokas (2008a). However, our study does not include the account activity (measured by the total number of transactions), due to incomplete information (data were only available from 2013).

The profit efficiency measure reflects the most efficient level of overall costs for generating profits, analysing how each branch uses its resources (inputs) to generate revenues such as interest income and non-interest income from commissions. In the present study, we focus on the efficiency of use of personnel expenses, operational expenses and interest expenses to generate interest and fee incomes (Oral \& Yolalan, 1990). The inputs used are personnel expenses, operating costs and interest expenses, and the output variable is the gross margin obtained by the branch, i.e. the total income - net interest income plus noninterest (fee) income. ${ }^{11}$

All value data are in constant 2011 euros (i.e. we used the consumer price index of the local market with respect to the base period 2011).

The input-output variables we use have been identified in many DEA studies focusing on bank branches (see Camanho \& Dyson, 1999, 2006; Paradi \& Zhu, 2013, among others). However, Fethi and Pasiouras (2010) concluded that although there is general agreement about the main categories of inputs and outputs, there is little consistency with respect to the specific inputs/outputs that should be used.

As stated in Section 3, in this study input-orientation technology is used for the overall efficiency assessment. ${ }^{12}$

\subsubsection{Environmental factors}

Several environmental factors were included in the analysis to account for operational and profit efficiencies. Following the empirical literature on bank branches cited in Section 2, we considered two groups of factors, one related to the bank's own performance metrics and the other related to other branch-specific characteristics, depending on data availability.

\subsubsection{Bank's own performance metrics}

The bank examined in this study uses several measures to measure branch performance, taking into account the competitive pressure and tight control exerted in this respect in the Spanish banking industry. For the present analysis, we focused on the two most significant measures of bank-metric performance for each branch, namely the magnitude of deviations of gross margin (or total income) from targets (calculated as the absolute value of deviations from gross margin objectives) and the productivity based on value $(\mathrm{PBV})$ in percentage terms.

In recent years, branch network functions have been valued by calculating the net interest income and the non-interest (fee) income generated by each DMU. The purpose of budgetary control is to detect and analyse deviations from financial objectives, as an essential part of business planning. One means of doing so is to analyse the 
difference between expected and real total income, this deviation usually being calculated both in absolute value and as a percentage.

PBV measures commercial activity in terms of the net present value generated by an operation, taking into account variables such as the volume of the operation, its price, term and risk, and the fact that a transaction contracted in a given year will generate income in subsequent years. PBV is measured quarterly from the corresponding sales reports. These contain three sections - resources, investment and products - and are monitored not only at the unit level but also for each unit manager with sales responsibility. PBV is calculated as an index, and so it is expressed in percentage units. Other methods are based on balance sheet and profit and loss statements for each unit.

\subsubsection{Other bank branch characteristics}

Several variables were included as other bank branch factors ${ }^{13}$ : First, the experience (or age) of the branch as a proxy of its ability (unobserved factor) to remain in the market. This variable allows us to evaluate the learning-by-doing or learning curve, and is expressed as the number of years the branch has been operational. ${ }^{14}$ Second, we included expected loan loss impairment as a measure of the bank's evaluation of the risk of credit default. From another perspective, it is a measure of the adequacy of credit risk management. Hence, the greater the expected loan loss impairment, the greater the risk. ${ }^{15}$ Third, we included two location variables: the geographic zone (districts or administrative areas) in which the bank branch is located, and a dummy variable termed market size, which distinguishes urban from rural branches, independently of the district. Fourth, we identified the number of branch employees with European Financial Advisor certification, as a measure of employee quality. Fifth, we included the branch's specialisation in product sales (such as specific products and mortgages for individuals, or products for businesses). ${ }^{16}$ Finally, we included a dummy variable termed bailout/regulatory reform, which took the value 1 if the branch operations considered were for the year 2012, and 0 otherwise.

Table 1 shows descriptive statistics for the variables used. Some of these variables represent counts and others are monetary values. The overall sample period is 20112014. In this table, we distinguish between inputs and outputs and the environmental factors used to explain estimated efficiencies. The descriptive statistics used, for all the study variables, were the average, the standard deviation and the 10th, 25th, 50th, 75th and 90th percentiles available for each variable, per year.

On average, each branch had four employees and negotiated values of $€ 11,053$ for deposits and $€ 31,793$ for loans. The average operating cost was $€ 143,897$, the average deviation between real and expected gross margin was 0.003, and the PBV was 1.15. The majority of branch employees had no EFA certification, most bank branches were located in cities and they specialised in product sales to individuals.

\subsection{Estimated efficiencies}

In this section, we present the results for the technical and scale efficiencies obtained by DEA, together with efficiency estimates obtained by $\mathrm{FDH}$, the robust non-parametric order- $\alpha$ and the efficiencies derived from applying Daraio and Simar's procedure (see Section 3 for a description of all these methods). In the latter case, order- $\alpha$ partial frontier analysis was used to detect potential outliers in the data, after which non- 


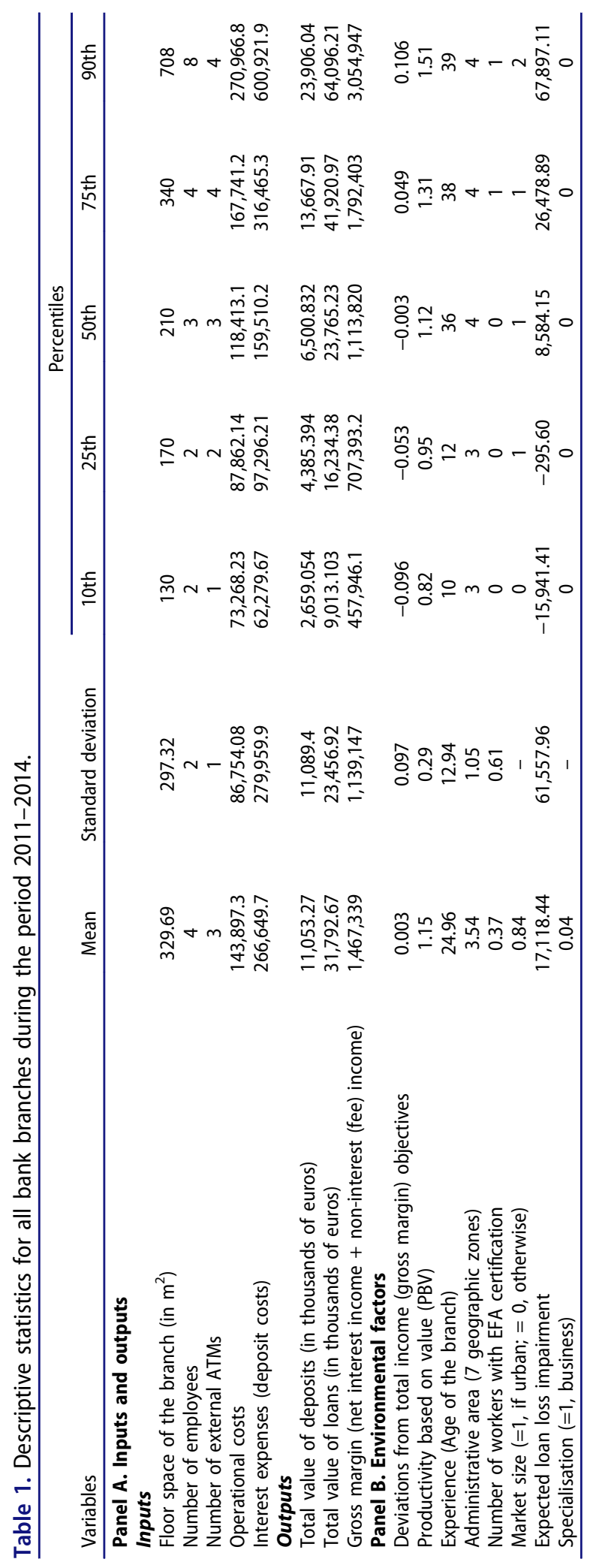


parametric classic efficiency analysis by DEA and FDH was conducted. This procedure enabled us to compare the results obtained from classical methods with those designed to manage the question of outliers.

\subsubsection{DEA-VRS, FDH, order-a and partial frontier based-outlier estimates}

In this section, we focus on estimates of efficiency based on variable returns to scale technology, using DEA, FDH and order- $\alpha$, together with the Daraio and Simar procedure. The different results obtained are presented for comparison. In all cases, the input orientation was used. DEA-CRS was also estimated, but as there are scale inefficiencies, and for the sake of brevity, these results are not shown. Nevertheless, they are available from the authors on request.

Table 2 shows the descriptive statistics for the efficiency scores, where $\widehat{\bar{\theta}}_{\text {method }}$ denotes the mean efficiency estimator by method: DEA-VRS, FDH and order- $\alpha$, respectively, and where the partial frontier-based outliers are obtained by DEA-VRS and FDH. Specifically, information related to the number of observations, the average and the standard deviation, the maximum and minimum values, and the 10th, 25th, 50th, 75th and 90th percentiles is available for each variable, for every year. A $\widehat{\bar{\theta}}_{\text {method }}$ score equal to 1 represents full efficiency while a value of less than one represents inefficiency. We also show the percentage of fully efficient (Eff) and super-efficient (SEff) bank branches, respectively $\left(\hat{\bar{\theta}}_{\text {order }-\alpha}>1\right)$, thus revealing the distribution of efficiencies.

In general, the efficiencies obtained are left-skewed, and those from robust estimators (order- $\alpha$ ) are always higher than those from non-parametric estimators such as DEAVRS and FDH. For example, the estimates of the mean efficiency are ordered as $\widehat{\bar{\theta}}_{D E A-V R S}<\widehat{\bar{\theta}}_{F D H}<\widehat{\bar{\theta}}_{\text {order- } \alpha}$, where $\alpha$ (the tuning parameter that determines the number of super-efficient branches) is different each year. In general, these results indicate that taking into account outliers (super-efficient branches) using order- $\alpha$ provides more consistent estimates of efficiencies than is possible with traditional DEA and FDH methods. Note that with order- $\alpha$, the value of $\alpha$ is calculated as the suggested point of discontinuity, obtained by using order- $a$-based outlier detection and is related to prime suggestion by criterion smoothing at $\alpha$, following Daraio and Simar's (2007) procedure. The results associated with the share of super-efficient units may appear improbable, at around $80 \%$ (i.e. there would seem to be too many DMUs beyond the frontier), in certain years. ${ }^{17}$ To investigate and account for these surprising results, we conducted a detailed comparison with other robust non-parametric methods such as order- $m$. The results obtained (not shown here, for the sake of brevity, but available on request from the authors) indicate the existence of similarities between the order- $\alpha$ and order- $m$ estimates for the different values chosen $(m=10,25,50,100$ and 250). Our conclusion, in this case, is that robust non-parametric methods reveal the existence of a large proportion of very well managed branches.

In general, the time path of efficiencies between 2011 and 2014 is stable according to the classical methods of estimation, in both dimensions, although there is a slight increase in the DEA and FDH based-outlier, despite the 2012 bailout of the Spanish bank system.

Focusing on pooled results, the full frontier results indicate that average managerial inefficiency (DEA-VRS) was around 14\% during the overall period, for the operational 


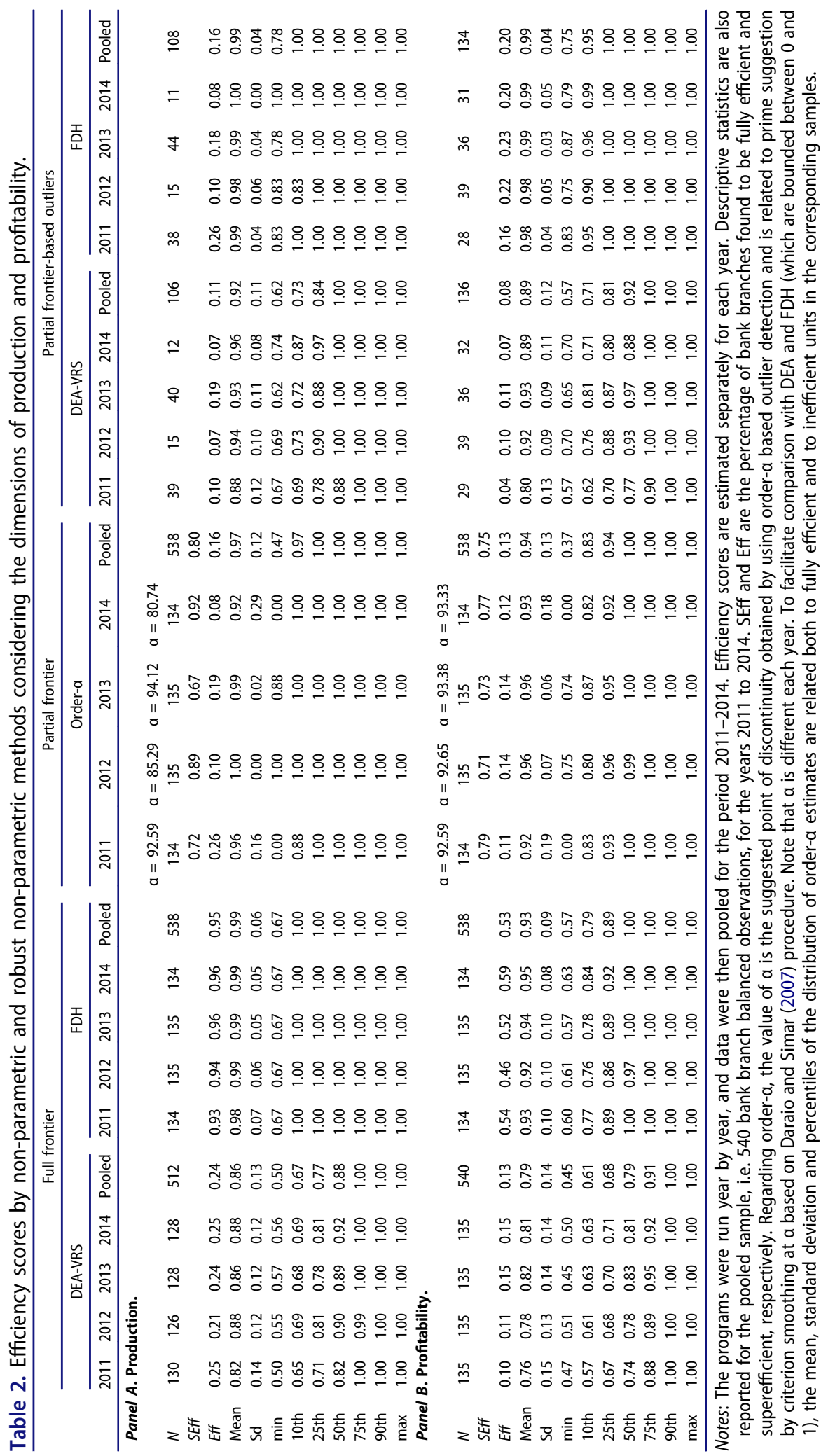


dimension, and $21 \%$ for the profitability dimension. The FDH approach gave values of $1 \%$ and $7 \%$, which are lower than those obtained by DEA-VRS. However, focusing on the partial frontier-based outliers, it is interesting to note that during the study period, $80 \%$ of the bank branches considered were super-efficient in the production dimension, but only $75 \%$ were super-efficient with respect to profitability. The corresponding DEA-VRS and $\mathrm{FDH}$ results indicate that mean inefficiencies are lower than with non-parametric methods. The scores obtained in this respect were $4 \%$ and $11 \%$, respectively, with DEA-VRS, but only $1 \%$ in each case with FDH.

In general, high levels of efficiency were recorded in both dimensions, although there were differences according to the technology employed (especially between DEA-VRS and FDH). When Daraio and Simar's procedure was used, based on partial frontier analysis and taking into account the outliers excluded by the DEA-VRS and FDH methods, the resulting efficiencies were higher than those obtained by the classical methods in which outliers were not addressed. Therefore, we can conclude that when super-efficient observations are allowed to be located beyond the estimated productionpossibility frontier, the efficiencies obtained are higher than with classical methods, in both the production and the profitability dimensions. It is important to note that these results also indicate that managers act correctly to achieve their objectives, in both approaches.

\subsubsection{Scale efficiency estimates}

The evaluation of scale efficiency scores is highly important to bank management. Scale efficiency indicates how successfully a branch is operating at its optimum scale; a scaleefficient branch works at the most productive scale size. Achievement of this optimum scale contributes to operational efficiency.

In this section, we present the results obtained for scale efficiencies for full frontier and for partial frontier-based outliers using DEA (Scale-DEA).

Estimation of the DEA-CRS (CCR) and DEA-VRS (BCC) models enabled us to determine global technical efficiency and pure technical efficiency, respectively. The scale efficiency score was calculated by dividing CCR by BCC. The NIRS model was also applied to evaluate the returns to scale obtained by each bank branch. Hence, for a particular branch, we can evaluate whether the NIRS technical efficiency score is equal to the BCC (VRS) technical efficiency score. If they are unequal, then increasing returns to scale (IRS) exist for that DMU. If they are equal, there are decreasing returns to scale (DRS).

Table 3 shows a numerical description of these results, listing the number of observations, the average and the standard deviation, the maximum and minimum values and the 10th, 25th, 50th, 75th and 90th percentiles available for each variable, per year. The table also shows the percentage of constant returns to scale (CRS), using CRS technology to estimate GTE, together with increasing and decreasing returns to scale (IRS and DRS, respectively) regarding NIRS technology. The latter indicators reveal whether scale inefficiencies are due to CRS, IRS or DRS.

On average, the time path of scale efficiencies is stable over time, with only slight differences. Focusing on the pooled data, the full frontier estimates and partial frontierbased outlier estimates are similar in both dimensions, with average scale efficiencies of $82 \%$ and $83 \%$ for production and $89 \%$ and $87 \%$ for profitability. For example, given these 
Table 3. Scale efficiency estimates.

\begin{tabular}{|c|c|c|c|c|c|c|c|c|c|c|}
\hline & \multicolumn{6}{|c|}{ Full frontier } & \multicolumn{4}{|c|}{ Partial frontier-based outliers } \\
\hline & \multicolumn{6}{|c|}{ Scale-DEA } & \multicolumn{4}{|c|}{ Scale-DEA } \\
\hline & 2011 & 2012 & 2013 & 2014 & Pooled & 2011 & 2012 & 2013 & 2014 & Pooled \\
\hline \multicolumn{11}{|c|}{ Panel A. Production. } \\
\hline$N$ & 130 & 126 & 128 & 128 & 512 & 39 & 15 & 40 & 12 & 106 \\
\hline Eff & 0.11 & 0.12 & 0.12 & 0.12 & 0.12 & 0.21 & 0.33 & 0.25 & 0.50 & 0.21 \\
\hline Mean & 0.82 & 0.82 & 0.82 & 0.82 & 0.82 & 0.81 & 0.85 & 0.81 & 0.88 & 0.83 \\
\hline Sd & 0.20 & 0.19 & 0.18 & 0.18 & 0.19 & 0.23 & 0.20 & 0.23 & 0.29 & 0.23 \\
\hline $\min$ & 0.00 & 0.28 & 0.26 & 0.33 & 0.00 & 0.00 & 0.42 & 0.29 & 0.00 & 0.00 \\
\hline 10th & 0.51 & 0.53 & 0.52 & 0.53 & 0.53 & 0.46 & 0.51 & 0.38 & 0.71 & 0.44 \\
\hline 25th & 0.76 & 0.73 & 0.75 & 0.73 & 0.75 & 0.66 & 0.80 & 0.72 & 0.93 & 0.72 \\
\hline 50th & 0.86 & 0.87 & 0.87 & 0.88 & 0.87 & 0.91 & 0.93 & 0.93 & 1.00 & 0.94 \\
\hline 75th & 0.99 & 0.99 & 0.98 & 0.98 & 0.98 & 1.00 & 1.00 & 1.00 & 1.00 & 1.00 \\
\hline 90th & 1.00 & 1.00 & 1.00 & 1.00 & 1.00 & 1.00 & 1.00 & 1.00 & 1.00 & 1.00 \\
\hline $\max$ & 1.00 & 1.00 & 1.00 & 1.00 & 1.00 & 1.00 & 1.00 & 1.00 & 1.00 & 1.00 \\
\hline \multicolumn{11}{|c|}{ Returns to scale (\%) } \\
\hline CRS & 0.11 & 0.12 & 0.12 & 0.10 & 0.11 & 0.21 & 0.33 & 0.25 & 0.05 & 0.21 \\
\hline IRS & 0.81 & 0.81 & 0.81 & 0.84 & 0.82 & 0.74 & 0.40 & 0.67 & 0.27 & 0.52 \\
\hline DRS & 0.08 & 0.07 & 0.07 & 0.05 & 0.07 & 0.05 & 0.27 & 0.08 & 0.00 & 0.10 \\
\hline \multicolumn{11}{|c|}{ Panel B. Profitability. } \\
\hline$N$ & 135 & 135 & 135 & 135 & 540 & 29 & 39 & 36 & 32 & 136 \\
\hline Eff & 0.05 & 0.07 & 0.03 & 0.05 & 0.05 & 0.17 & 0.08 & 0.14 & 0.13 & 0.13 \\
\hline Mean & 0.93 & 0.88 & 0.87 & 0.89 & 0.89 & 0.96 & 0.83 & 0.84 & 0.87 & 0.87 \\
\hline Sd & 0.09 & 0.15 & 0.16 & 0.13 & 0.14 & 0.05 & 0.14 & 0.15 & 0.14 & 0.13 \\
\hline $\min$ & 0.59 & 0.31 & 0.37 & 0.38 & 0.31 & 0.83 & 0.50 & 0.57 & 0.50 & 0.50 \\
\hline 10th & 0.78 & 0.67 & 0.61 & 0.71 & 0.69 & 0.89 & 0.65 & 0.65 & 0.68 & 0.66 \\
\hline 25th & 0.92 & 0.82 & 0.83 & 0.86 & 0.86 & 0.91 & 0.70 & 0.70 & 0.75 & 0.76 \\
\hline 50th & 0.97 & 0.94 & 0.94 & 0.95 & 0.95 & 0.98 & 0.86 & 0.89 & 0.93 & 0.91 \\
\hline 75th & 0.99 & 0.99 & 0.98 & 0.97 & 0.99 & 1.00 & 0.97 & 0.99 & 0.97 & 0.99 \\
\hline 90th & 1.00 & 1.00 & 1.00 & 1.00 & 1.00 & 1.00 & 1.00 & 1.00 & 1.00 & 1.00 \\
\hline $\max$ & 1.00 & 1.00 & 1.00 & 1.00 & 1.00 & 1.00 & 1.00 & 1.00 & 1.00 & 1.00 \\
\hline \multicolumn{11}{|c|}{ Returns to scale (\%) } \\
\hline CRS & 0.05 & 0.07 & 0.03 & 0.05 & 0.05 & 0.17 & 0.08 & 0.14 & 0.13 & 0.13 \\
\hline IRS & 0.71 & 0.80 & 0.75 & 0.72 & 0.74 & 0.72 & 0.90 & 0.67 & 0.59 & 0.72 \\
\hline DRS & 0.24 & 0.13 & 0.22 & 0.23 & 0.21 & 0.10 & 0.03 & 0.19 & 0.28 & 0.15 \\
\hline
\end{tabular}

Notes: The programs were run year by year, and data were then pooled for the period 2011-2014. Efficiency scores are estimated separately for each year. Descriptive statistics are also reported for the pooled sample, i.e. 540 bank branch balanced observations; for the years 2011 to 2014. Eff is the percentage of bank branches found to be fully efficient. Scale efficiency is calculated using order-a based outlier detection, and is related to prime suggestion by criterion smoothing at a based on Daraio and Simar (2007) procedure. Note that a is different each year. Table results for each year are not shown for the sake of brevity, but are available from the authors on request.

production results, scale inefficient branches could reduce their size by $18 \%$ and $17 \%$, respectively, without affecting their current output levels, thus making internal practice more efficient.

Focusing on the Scale-DEA-based outlier approach, the pooled results show that in the operational dimension, increasing the inputs by a given proportion would produce an increase in the same proportion (constant returns to scale, CRS) of the outputs. Hence, these branches were operating at their optimal productive scale. However, scale inefficiencies are mainly caused by IRS at most branches (around $52 \%)$. Therefore, increasing the inputs by a given proportion would increase the outputs by a greater proportion. Hence, these branches need to expand in order to achieve the optimal size (i.e. that at which there are constant returns to scale in the relationship between inputs and outputs). DRS is around $10 \%$, which indicates that the branches need to reduce their size to achieve optimal scale. In general, 
these results are similar to those reported by Camanho and Dyson (1999), but are in contrast to Paradi et al. (2011), for whom 76-84\% of inefficient branches were classified as CRS while only $2 \%$ were IRS. For these authors, a decrease in the branches' inputs might enable them to operate below their optimal scale.

Similar results were obtained using Scale-DEA-based outliers and profit efficiencies. In this case, the proportions of branches were 13\% (CRS), $72 \%$ (IRS) and 15\% (DRS).

\subsection{Relationship between efficiency estimates and bank branch factors}

This sub-section presents estimates of the linear regression model using Simar and Wilson's procedure, examining the relationship between efficiency and explanatory factors at the branch level (described in Section 4.1.2). Specifically, 300 bootstrap simulations were performed for classical DEA-VRS, Scale-DEA and FDH efficiency scores, and also for DEA and FDH-based outlier efficiency scores, for the sake of comparison.

For managerial purposes, the implications of this study can be derived from Tables 4 and 5, which show the coefficient and the standard errors for environmental factors regarding technical and scale efficiency, respectively. The results are presented as two groups for each dimension (production and profitability). The first group (i.e. the classical DEA and FDH methods) are non-based outlier estimations, and the second i.e. the DEA and FDH-based outliers, is composed of based outliers. Although there are seven geographic districts (Table 1), we used a dummy variable, termed Zone, taking one of two values: 1 if the branch is located in administrative area number 3 (where the bank's regional headquarters are located), and 0 otherwise. This approach allowed us to analyse the influence of the headquarters location on efficiency.

The results shown in these tables can be summarised as follows. For all models, the coefficient of standard deviation of estimated errors, $\sigma_{e}$, and the constant parameter in each model are both statistically significant at $1 \%$.

Table 4 (where FDH-based outliers in the production approach are not shown, as the estimation does not converge) reveals several interesting facts. First, there are more statistically significant coefficients for non-based outlier models than for based outliers, which indicates that outliers influence the results obtained. Second, with respect to the based outlier results, the coefficient of bailout is only positive and statistically significant in DEA-VRS. Therefore, bank branch efficiency increased in 2012 despite the bank bailout and the regulatory reforms enacted.

Third, the PBV coefficient is positive and statistically significant at 5\% in DEA-VRS both for the production approach and for the profit approach. This means that the bank's own performance metric is related to our estimated efficiencies, and therefore is a valid instrument for branch managers to implement operational and profitability policies. However, in terms of FDH, there is no such relationship; only the coefficient of $\mathrm{D}$ is positive and statistically significant at $10 \%$ in the FDH-based outliers. Finally, the results for other branch characteristics are mixed and ambiguous. In general, few coefficients are statistically significant, possibly due to the limited sample size (around 100 observations). However, the coefficients of EFA and expected loan loss impairment are never statistically significant, while those of location and specialisation are positive and statistically significant at 5\% in the FDH-based outlier technology and profitability 


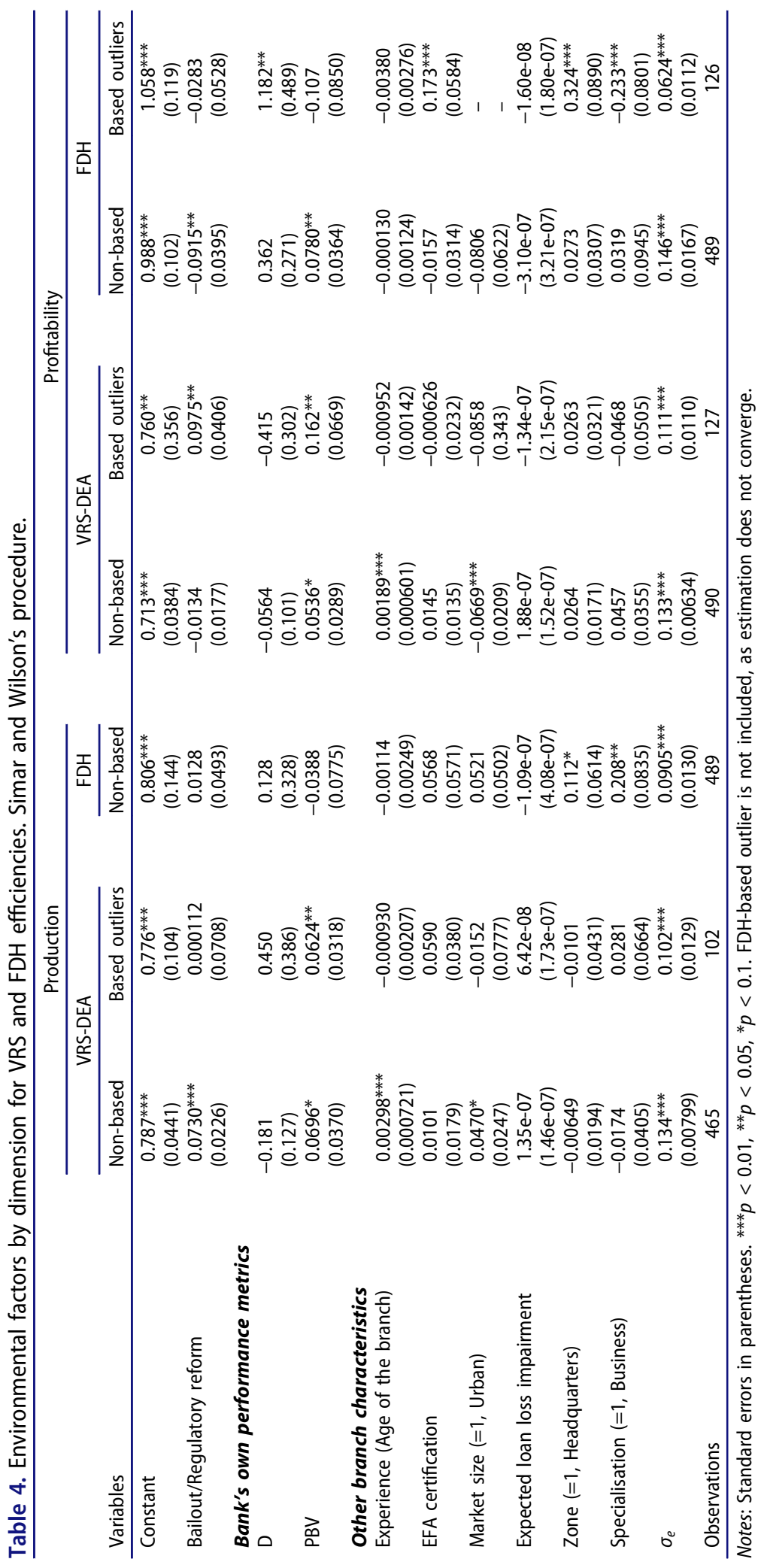


Table 5. Environmental factors by dimension for scale efficiencies (Scale-DEA). Simar and Wilson's procedure.

\begin{tabular}{|c|c|c|c|c|}
\hline \multirow[b]{3}{*}{ Variables } & \multicolumn{2}{|c|}{ Production } & \multicolumn{2}{|c|}{ Profitability } \\
\hline & \multicolumn{2}{|c|}{ Scale-DEA } & \multicolumn{2}{|c|}{ Scale-DEA } \\
\hline & Non-based & Based outliers & Non-based & Based outliers \\
\hline Constant & $\begin{array}{l}0.610^{* * *} \\
(0.171)\end{array}$ & $\begin{array}{c}0.242 \\
(0.254)\end{array}$ & $\begin{array}{l}0.712^{* * *} \\
(0.226)\end{array}$ & $\begin{array}{l}0.665^{* *} \\
(0.266)\end{array}$ \\
\hline Bailout/regulatory reform & $\begin{array}{c}0.0401 \\
(0.0895)\end{array}$ & $\begin{array}{c}-0.0679 \\
(0.144)\end{array}$ & $\begin{array}{c}-0.167 \\
(0.144)\end{array}$ & $\begin{array}{c}-0.133 \\
(0.0902)\end{array}$ \\
\hline \multicolumn{5}{|c|}{ Bank's own performance metrics } \\
\hline $\mathrm{D}$ & $\begin{array}{c}-0.215 \\
(0.322)\end{array}$ & $\begin{array}{c}-0.0901 \\
(0.686)\end{array}$ & $\begin{array}{c}0.279 \\
(0.496)\end{array}$ & $\begin{array}{c}0.815 \\
(0.684)\end{array}$ \\
\hline PBV & $\begin{array}{c}-0.0178 \\
(0.121)\end{array}$ & $\begin{array}{c}0.100 \\
(0.179)\end{array}$ & $\begin{array}{c}-0.249 \\
(0.189)\end{array}$ & $\begin{array}{c}-0.199 \\
(0.156)\end{array}$ \\
\hline \multicolumn{5}{|l|}{ Other branch characteristics } \\
\hline Experience (Age of the branch) & $\begin{array}{l}0.0100^{* * *} \\
(0.00377)\end{array}$ & $\begin{array}{c}0.0116^{* * *} \\
(0.00408)\end{array}$ & $\begin{array}{l}0.0381^{* *} \\
(0.0159)\end{array}$ & $\begin{array}{c}0.0105^{* * *} \\
(0.00393)\end{array}$ \\
\hline EFA certification & $\begin{array}{c}0.0253 \\
(0.0645)\end{array}$ & $\begin{array}{l}0.107 \\
(0.0884)\end{array}$ & $\begin{array}{c}0.0519 \\
(0.103)\end{array}$ & $\begin{array}{c}0.191^{* *} \\
(0.0780)\end{array}$ \\
\hline Market size $(=1$, Urban) & $\begin{array}{l}0.522^{* * *} \\
(0.106)\end{array}$ & $\begin{array}{l}0.508^{* * *} \\
(0.151)\end{array}$ & $\begin{array}{l}0.961^{* * *} \\
(0.326)\end{array}$ & $\begin{array}{c}0.283 \\
(0.194)\end{array}$ \\
\hline Expected loan loss impairment & $\begin{array}{c}1.38 \mathrm{e}-06^{*} \\
(7.85 \mathrm{e}-07)\end{array}$ & $\begin{array}{r}-1.16 \mathrm{e}-07 \\
(6.66 \mathrm{e}-07)\end{array}$ & $\begin{array}{c}-2.15 \mathrm{e}-06 \\
(1.50 \mathrm{e}-06)\end{array}$ & $\begin{array}{r}-1.25 \mathrm{e}-06^{*} \\
(6.72 \mathrm{e}-07)\end{array}$ \\
\hline Zone (=1, Headquarters) & $\begin{array}{c}-0.0626 \\
(0.0821)\end{array}$ & $\begin{array}{l}0.0388^{* * *} \\
(0.0126)\end{array}$ & $\begin{array}{c}0.0171 \\
(0.136)\end{array}$ & $\begin{array}{c}-0.0324 \\
(0.0780)\end{array}$ \\
\hline Specialisation (=1, Business) & $\begin{array}{l}3.948^{* * * *} \\
(1.527)\end{array}$ & $\begin{array}{c}1.812^{*} \\
(1.018)\end{array}$ & $\begin{array}{c}2.945^{*} \\
(1.624)\end{array}$ & $\begin{array}{l}0.967^{* *} \\
(0.449)\end{array}$ \\
\hline$\sigma_{e}$ & $\begin{array}{l}0.334^{* * *} \\
(0.0429)\end{array}$ & $\begin{array}{l}0.250^{* * *} \\
(0.0394)\end{array}$ & $\begin{array}{l}0.334^{* * *} \\
(0.0694)\end{array}$ & $0.208^{* * *}$ \\
\hline Observations & $\begin{array}{c}(0.0429) \\
465\end{array}$ & $\begin{array}{c}(0.0394) \\
101\end{array}$ & $\begin{array}{c}(0.0694) \\
490\end{array}$ & $\begin{array}{c}(0.0348) \\
127\end{array}$ \\
\hline
\end{tabular}

Notes: Standard errors in parentheses. ${ }^{* * *} p<0.01,{ }^{* *} p<0.05,{ }^{*} p<0.1$.

dimension. The coefficient of market size (i.e. rural vs. urban markets) is not statistically significant, thus indicating similar levels of efficiency in both types of market.

For the classical models, when the sample size is large and there are more inefficient branches, other relevant factors may also explain inefficiencies, especially in the profitability approach. However, many of the environmental factors we have considered are not relevant to explain the technical inefficiencies observed if we eliminate the super-efficient observations using Daraio and Simar's procedure with the order- $\alpha$ method, with the exception of PBV. Therefore, it is interesting to note that the non-detection of outliers may not only distort the efficiency values obtained but could also affect the regression results.

Focusing on the results in Table 5 (scale efficiencies) and partial frontier-based outliers, we see that many coefficients are statistically significant for the other branch characteristics, while those of the bank's own performance and bailout/regulatory reform are not statistically significant, in any of the models considered. Therefore, and unlike the situation reflected in Table 4, the bank's own metrics did not affect the scale efficiency in our sample period. It is also noteworthy that the non-based and based outlier models yield differing results, although there are some similarities in terms of other branch characteristics, which present many parameters with similar signs and that are statistically significant.

For example, the coefficients of experience and specialisation are always positive and statistically significant for all models, and that of market size is statistically significant and positive for three models. Therefore, we have found that efficiency scores are different in urban and rural areas in our bank. The coefficient of expected loan loss impairment is negative 
and statistically significant for two models, while that of EFA certification is statistically significant for one profitability model. Jointly, these findings indicate that efficiency increases as these coefficients increase, with the exception of expected loan loss impairment; in the latter case, an increase in credit provisions is associated with decreased efficiency.

\section{Discussion and conclusions}

The aim of this study is to fill a research gap in efficiency studies of Spanish bank branches and to analyse the performance (efficiency) of bank branches and managers during a period in which financial institutions had to adapt to a new macroeconomic scenario, to regulatory changes, to the effects of a further recession in the Spanish economy in the first quarter of 2012, and to the substantial restructuring of the banking industry that took place following the bailout of the Spanish banking system in 2012. To date, no research has been published concerning measures of technical and scale efficiencies and the evaluation of the effects of environmental factors relevant to bank branches in Spain.

This study was conducted to evaluate several measures of bank branch efficiency, with specific regard to the performance of a major Spanish commercial bank. Unlike previous studies such as Oral and Yolalan (1990), Camanho and Dyson (2005b), Portela and Thanassoulis (2007), Giokas (2008a), Paradi et al. (2011) and Aggelopoulos et al. (2013), we estimated technical efficiency (pure and global) and scale efficiencies using not only DEA, but also FDH and order- $\alpha$, taking into account that the latter approach deals more efficiently with outliers (super-efficient branches). In addition, we studied the relationships between efficiency estimates and economic determinants of efficiency such as bank-metric performance assessment, together with other branch-specific factors like market size, staff quality, location, specialisation in certain product areas (individual or business customers), expected loan loss impairment and the effect of the year 2012 (i.e. the bailout of the Spanish banking industry and the secondary recession affecting the Spanish economy).

The following main results were obtained. Firstly, regarding production technology, CRS is not preferred to VRS at the branch level, and scale efficiencies exist. In general, previous empirical studies have reported similar results. For example, Camanho and Dyson (2005a) concluded that the frontier should be estimated assuming VRS for the production approach. Secondly, it should be taken into account that our non-parametric efficiency estimates are sensitive to the presence of outliers, or superefficient branches. Our results, from applying Daraio and Simar (2007) procedure and then using DEA and FDH, show that the efficiencies estimated using the full frontier-based outlier approach are slightly higher than those derived by classical non-parametric efficiency methods. Therefore, the existence of super-efficient branches affected the regression results. Thirdly, the bank branches in our sample were mostly very well managed and achieved generally high levels of technical and scale efficiency, relatively close to the frontier in both the operational and the profitability dimensions, in the new regulatory scenario and also during the period of bank-sector restructuring. We conclude, therefore that the majority of branch managers correctly manage their inputs and outputs, encouraged in this by the strict rules imposed by Head Office and the need to comply with banking regulation and supervision.

Our study also revealed the existence of causality between variables of interest which could contribute to a better understanding of branch performance. For example, regarding technical (pure) efficiency, the bank's own performance metrics (e.g. PBV) can be compared with 
technical efficiency scores. Therefore, our results validate the use of non-parametric methods, which corroborates the findings of empirical research comparing DEA and the bank's own metrics (Lovell \& Pastor, 1997; Berger and Humpfrey, 1997; Parkan \& Wu, 1999; among others). On the other hand, there is no clear picture of other variables affecting technical efficiency such as quality of personnel (EFA) or measures of risk, and so managers cannot perform segmentation in terms of these variables. However, as regards the optimal scale size, bank managers should take into account that scale efficiency might vary depending on the experience, type of market and specialisation and risk measures, but not on the bank's own performance metrics.

Finally, from the business practice standpoint, it is noteworthy that the current pressures exerted on their margins, due to fierce competition in this sector, have forced banks to implement new strategies to improve business performance, offering innovative products and services and seeking greater efficiency and productivity. Our results have various implications for business practice, with respect to branch efficiency in particular. Firstly, managers can simultaneously apply more than one method to evaluate and compare branch efficiency and performance (i.e. DEA, FDH and order- $\alpha$, among other techniques). This would enable them to better identify opportunities for improvement, to monitor the pattern of operations and the stability or otherwise of each branch over time, and to construct models to assist with decision-making. Secondly, because no single model can fully capture the multi-role nature of bank branches, as has been shown in empirical research, managers should decide for themselves on the best ways to measure the performance of their operating units, with respect to prescribed strategy (e.g. operational and/or profitability dimensions) and adjust managerial procedures if necessary. Thirdly, technical efficiency scores can be used to evaluate branch performance, complementing the bank's own performance metrics based on PBV. Thus, each manager should consider the most appropriate strategies for the case in question to increase productivity and performance and thus meet the financial targets established for the branch.

In conclusion, both non-parametric and robust non-parametric methods are appropriate for use in a dynamic environment and can easily be modified to address changing needs, thus revealing the strengths, weaknesses and improvement capabilities of bank branches and providing useful information regarding performance, taking into account that managers, as a business priority, are obliged to maximise branch efficiency.

Our paper presents at least two serious limitations, which should be taken into account; on the one hand, the volume of data and the study period are both very limited. On the other, a further-reaching comparison is needed with other methods such as order- $m$. Future research in this field, therefore, should include a more detailed analysis of non-parametric estimation regarding superefficient scores, which are higher than have been reported in empirical studies that used this method in other business sectors. It would also be useful to investigate the outcome of employing the Malmquist Total Factor Productivity (TFP) index approach, which could be based on DEA but also on robust non-parametric methods such as order- $m$, and other DEA methods based on cost efficiency (to evaluate the ability of a branch to produce current outputs at minimal cost), and to study the question of allocative efficiency (i.e. the ability of the branch to use its inputs in optimal proportions, given their input prices). 


\section{Notes}

1. The non-parametric frontier approach using DEA or FDH requires minimal assumptions regarding the structure of the production and does not impose restrictions on the functional form relating inputs and outputs. Because it does not take into account noise in the data, it implicitly assumes that every deviation from the frontier can be considered as inefficiency. However, in parametric SFA, assumptions are made both about the functional form and about the distribution of the two types of error: an idiosyncratic error term and the inefficiency error term (i.e. the deviation from the frontier).

2. These authors examined commercial banks, savings banks and credit unions and calculated both cost and revenue efficiency. Their results indicated that commercial banks were more efficient than savings banks and credit unions. However, during the crisis years, the differences between these institutions shrank dramatically, especially as regards cost efficiency.

3. See the McKinsey Retail Banking Multichannel Survey, 2016; McKinsey \& Company.

4. Of the 80 papers published, the largest number focuses on bank branches in Canada, followed by those on Greece, Portugal, USA and UK, respectively.

5. The same authors (p. 69) indicated that from a management perspective, the literature has reported two main types of environmental factors: region-specific (local economic growth, local unemployment rate, local community types, different opening hours, among others) and corporate-specific variables (different areas of specialisation, such as loans, mortgages, deposits, gold trading and foreign exchanges).

6. It is noteworthy that under constant returns to scale, input and output-oriented models are equivalent. However, under variable returns to scale, they are different concepts, and can lead to different efficiency measures being determined for inefficient branches.

7. If non-decreasing returns to scale (NDRS) are considered, the convexity restriction is replaced by $\sum_{j=1}^{n} \lambda_{j} \geq 1$.

8. This seems an attractive property of FDH since it is frequently difficult to find a good theoretical or empirical justification for postulating convex production sets in efficiency analysis. FDH is sometimes economically more meaningful than convex monotone hull, under non-trivial alternative economic conditions. Hence, FDH technical efficiency measures remain meaningful for theories of the firm that allow for imperfect competition or uncertainty.

9. The main difference from order- $m$ is that order- $\alpha$ does not require resampling, and so the estimation process is faster.

10. It is among the core of strong banks that are well managed, sufficiently capitalised and apparently resilient to further shocks. Other, more vulnerable, institutions with large proportions of their balance sheets linked to the real estate sector require further restructuring and recapitalisation.

11. The gross margin is measured as the sum of the OPOs and the interest margin. OPOs are defined as the charges imposed by the bank for the provision of all types of services (total commissions + exchange differences + rest of financial transactions). The interest margin is the difference between the interest charged for credit and financial investments made (Assets) less the interest paid to customers and other lenders for the money deposited in the bank (Liabilities).

12. We also calculated output-oriented efficiency, but the results are not shown, for the sake of brevity. These results are available on request from the authors.

13. They are mainly region-specific, corporate-specific and other branch-specific factors beyond the manager's control.

14. The number of years a company has been in existence can be a good indicator of its experience or accumulation of experience (Bernini \& Guizzardi, 2010).

15. Loan loss impairment is used by some authors as input in a profit approach (Giokas, 2008a), in the view that this factor could reduce profit efficiency. However, we use the expected loan loss impairment which is related to a risk measure for the branch. More specifically, if there is a high probability that the loan will become delinquent, it is considered an expected loss. No provisions are made in this respect. 
16. These categories are defined by the bank itself.

17. Paradi and Zhu (2013) pointed out that a large number of branches are located at the efficient frontier, typically $25-50 \%$, as bank branches, in general, tend to be very well managed (due to the strict policies imposed by central offices and the government regulator).

\section{Disclosure statement}

No potential conflict of interest was reported by the authors.

\section{ORCID}

Jorge V. Pérez-Rodríguez (D) http://orcid.org/0000-0002-6738-9191

\section{References}

Aggelopoulos, E., Georgopoulos, A., \& Siriopoulos, C. (2013). Comparative efficiency analysis of Greek bank branches in the light of the financial crisis. CiteSeerX.psu:10.1.1.366.723. Retrieved from http://citeseerx.ist.psu.edu/viewdoc/summary?doi=10.1.1.366.723

Alirezaee, M. R., \& Afsharian, M. (2007). Model improvement for computational difficulties of DEA technique in the presence of special DMUs. Applied Mathematics and Computation, 186, 1600-1611.

Al-Tamimi, H. A. H., \& Lootah, A. M. (2007). Evaluating the operational and profitability efficiency of a UAE-based commercial bank. Journal of Financial Services Marketing, 11, 333-348.

Aragon, Y., Daouia, A., \& Thomas-Agnan, C. (2005). Nonparametric frontier estimation: A conditional quantile based approach. Econometric Theory, 21, 358-389.

Asmild, M., Paradi, J., Aggarwal, V., \& Schaffnit, C. (2004). Combining DEA window analysis with the Malmquist index approach in a study of the Canadian banking industry. Journal of Productivity Analysis, 21, 67-89.

Asmild, M., \& Tam, F. (2007). Estimating global frontier shifts and global Malmquist indices. Journal of Productivity Analysis, 27, 137-148.

Athanassopoulos, A. D. (1997). Service quality and operating efficiency synergies for management control in the provision of financial services: Evidence from Greek bank branches. European Journal of Operational Research, 98, 300-313.

Athanassopoulos, A. D. (1998). Nonparametric frontier models for assessing the market and cost efficiency of large-scale bank branch networks. Journal of Money, Credit, and Banking, 30, 172-192.

Banker, R. D., Charnes, A., \& Cooper, W. W. (1984). Some models for estimating technical and scale inefficiencies in data envelopment analysis. Management Science, 30, 1078-1092.

Berg, S. A., Førsund, F. R., Hjalmarsson, L., \& Suominen, M. (1993). Banking efficiency in Nordic countries. Journal of Banking and Finance, 17, 371-388.

Berger, A. N., \& Humphrey, D. B. (1997). Efficiency of financial institutions: International survey and directions for future research. European Journal of Operational Research, 98, 175-212.

Berger, A. N., Leusner, J. H., \& Mingo, J. J. (1997). The efficiency of bank branches. Journal of Monetary Economics, 40, 141-162.

Bernini, C., \& Guizzardi, A. (2010). Internal and locational factors affecting hotel industry efficiency: Evidence from Italian business corporations. Tourism Economics, 16(4), 883-913.

Cabrera-Suárez, I., \& Pérez-Rodríguez, J. V. (2017). Bank branch performance and cost efficiency: A stochastic frontier panel data approach. Mimeo: Department of Quantitative Methods, University of Las Palmas de Gran Canaria.

Camanho, A. S., \& Dyson, R. G. (1999). Efficiency, size, benchmarks and targets for bank branches: An application of data envelopment analysis. Journal of the Operational Research Society, 50, 903-915.

Camanho, A. S., \& Dyson, R. G. (2005a). Cost efficiency, production and value-added models in the analysis of bank branch performance. Journal of the Operational Research Society, 56, 483-494. 
Camanho, A. S., \& Dyson, R. G. (2005b). Cost efficiency measurement with price uncertainty: A DEA application to bank branch assessments. European Journal of Operational Research, 161, 432-446.

Camanho, A. S., \& Dyson, R. G. (2006). Data envelopment analysis and Malmquist indices for measuring group performance. Journal of Productivity Analysis, 26, 35-49.

Caves, D. W., Christensen, L. R., \& Diewert, W. E. (1982). The economic theory of index numbers and the measurement of input, output, and productivity. Econometrica : Journal of the Econometric Society, 50, 1393-1414.

Cazals, C., Florens, J. P., \& Simar, L. (2002). Nonparametric frontier estimation: A robust approach. Journal of Econometrics, 106, 1-25.

Charnes, A., Cooper, W. W., \& Rhodes, E. L. (1978). Measuring the efficiency of decision making units. European Journal of Operational Research, 2, 429-444.

Chortareas, G., Girardone, C., \& Ventouri, A. (2009). Efficiency and productivity of Greek banks in the EMU era. Applied Financial Economics, 16, 1317-1328.

Coelli, T., Prasada Rao, D., O’ Donnell, C., \& Battese, G. (2005). An introduction to efficiency and productivity analysis (2nd ed.). New York, NY: Springer.

Cook, W. D., Seiford, L. M., \& Zhu, J. (2004). Models for performance benchmarking: Measuring the effect of e-business activities on banking performance. Omega, 32, 313-322.

Cook, W. D., \& Zhu, J. (2006). Incorporating multiprocess performance standards into the DEA framework. Operations Research, 54, 656-665.

Cuesta, R. A., \& Orea, L. (2002). Mergers and technical efficiency in Spanish savings banks: A stochastic distance function approach. Journal of Banking \& Finance, 26(12), 2231-2247.

Daraio, C., \& Simar, L. (2007). Advanced Robust and Nonparametric Methods in Efficiency Analysis: Methodology and Applications. New York: Springer.

Das, A., Ray, S. C., \& Nag, A. (2009). Labor-use efficiency in Indian banking: A branch-level analysis. Omega, 37, 411-425.

Deprins, D., Simar, L., \& Tulkens, H. (1984). Measuring labor-efficiency in post offices. In M. Marchand, P. Pestieau, \& H. Tulkens (Eds.), The performance of public enterprises: Concepts and measurement (pp. pp. 243-267). Chap. 10. Amsterdam: North-Holland.

Deville, A. (2009). Branch banking network assessment using DEA: A benchmarking analysis-A note. Management Accounting Research, 20, 252-261.

Drake, L., \& Howcroft, B. (1994). Relative efficiency in the branch network of a UK bank: An empirical study. Omega, 22, 83-90.

Drake, L., \& Howcroft, B. (2002). An insight into the size efficiency of a UK bank branch network. Managerial Finance, 28, 24-36.

Färe, R., Grosskopf, S., Lindgren, B., \& Roos, P. (1993). Productivity developments in Swedish hospitals: A Malmquist output index approach. In A. Charnes, W. W. Cooper, A. Y. Lewin, \& L. M. Seiford (Eds.), Data envelopment analysis: Theory, methodology and applications (pp. 253-271). Boston: Kluwer.

Färe, R., Grosskopf, S., \& Lovell, C. A. K. (1985). The measurement of efficiency of production. New York, NY: Springer.

Färe, R., Grosskopf, S., Maudos, J., \& Tortosa-Ausina, E. (2010). Efficiency and market power in Spanish banking. 23rd Australasian Finance and Banking Conference 2010 Paper. SSRN. Retrived from https://ssrn.com/abstract=1662142.or.http://dx.doi.org/10.2139/ssrn.1662142

Färe, R., Grosskopf, S., Norris, M., \& Zhang, Z. (1994). Productivity growth, technical progress, and efficiency change in industrialized countries. American Economic Review, 84(1), 66-83.

Färe, R., Grosskopf, S., \& Russell, R. R. (1998). Index numbers: Essays in honour of Sten Malmquist. Dordreicht: Kluwer Academic Publishers.

Farrell, M. J. (1957). The measurement of productive efficiency. Journal of the Royal Statistical Society, 120, 253-290.

Fethi, M. D., \& Pasiouras, F. (2010). Assessing bank efficiency and performance with operational research and artificial intelligence techniques: A survey. European Journal of Operational Research, 204, 189-198. 
Fukuyama, H. (1995). Measuring efficiency and productivity growth in Japanese banking: A nonparametric frontier approach. Applied Financial Economics, 5, 95-107.

Giokas, D. I. (1991). Bank branch operating efficiency: A comparative application of DEA and the loglinear model. Omega, 19, 549-557.

Giokas, D. I. (2008a). Assessing the efficiency in operations of a large Greek bank branch network adopting different economic behaviors. Economic Modeling, 25, 559-574.

Giokas, D. I. (2008b). Cost efficiency impact of bank branch characteristics and location: An illustrative application to Greek bank branches. Managerial Finance, 34(3), 172-185.

Grifell, E., \& Lovell, C. A. K. (1997). The sources of productivity change in Spanish banking. European Journal of Operational Research, 98, 364-380.

Grosskopf, S. (1993). Efficiency and productivity. In H. O. Fried \& S. S. Schmidt (Eds.), The measurement of productive efficiency: Techniques and applications (pp. 160-194). Oxford: Oxford University Press.

Guzmán, I., \& Reverte, C. (2008). Productivity and efficiency change and shareholder value: Evidence from the Spanish banking sector. Applied Economics, 40(15), 2037-2044.

Krüger, J.J. (2012). A monte carlo study of old and new frontier methods for efficiency measurement. European Journal Of Operational Research, 222, 137-148. doi:10.1016/j. ejor.2012.04.026

Kumbhakar, S. C., \& Lovell, K. (2000). Stochastic frontier analysis. Cambridge, UK: Cambridge University Press.

Lovell, C. A. K., \& Pastor, J. T. (1997). Target setting: An application to a bank branch network. European Journal of Operational Research, 98, 290-299.

Manandhar, R., \& Tang, J. C. S. (2002). The evaluation of bank branch performance using data envelopment analysis: A framework. The Journal of High Technology Management Research, $13,1-17$.

Marzec, J., \& Osiewalski, J. (2008). Bayesian inference on technology and cost efficiency of bank branches. Bank i Kredyt, 9, 29-43.

Maudos, J. (1996). Eficiencia, cambio técnico y productividad en el sector bancario español: Una aproximación de frontera estocástica. Investigaciones Económicas, (20), 339-358.

Maudos, J. (2001). Rentabilidad, estructura de mercado y eficiencia en el sector bancario español. Revista de Economía Aplicada, 25(9), 193-207.

Maudos, J., \& Pastor, J. M. (2001a). La eficiencia del sistema bancario español en el contexto de la Unión Europea. Papeles de Economía Española, (84-85), 155-168.

Maudos, J., \& Pastor, J. M. (2001b). Cost and profit efficiency in banking: An international comparison of Europe, Japan and the USA. Applied Economics Letters, 8(6), 383-387.

Maudos, J., \& Pastor, J. M. (2003). Cost and profit efficiency in the Spanish banking sector (1985-1996): A non-parametric approach. Applied Financial Economics, 13(1), 1-12.

Maudos, J., Pastor, J. M., \& Pérez, F. (2002). Competition and efficiency in the Spanish banking sector: The importance of specialisation. Applied Financial Economics, 12, 505-516.

McEachern, D., \& Paradi, J. C. (2007). Intra- and inter-country bank branch assessment using DEA. Journal of Productivity Analysis, 27, 123-136.

Mukherjee, K., Ray, S. C., \& Miller, S. (2001). Productivity growth in large US commercial banks: The initial post-deregulation experience. Journal of Banking \& Finance, 25, 913-939.

Oral, M., \& Yolalan, R. (1990). An empirical study on measuring operating efficiency and profitability of bank branches. European Journal of Operational Research, 46, 282-294.

Orea, L., \& Kumbhakar, S. C. (2004). Efficiency measurement using a latent class stochastic frontier model. Empirical Economics, 29(1), 169-183.

Osiewalski, J., \& Marzec, J. (1998). Bayesian analysis of cost efficiency with an application to bank branches. In E. Miklaszewska (Ed.), Global Tendencies and Changes in East European Banking. Cracow: Jagiellonian University.

Paradi, J., Rouatt, S., \& Zhu, H. (2011). Two-stage evaluation of bank branch efficiency using data envelopment analysis. Omega, 39, 99-109.

Paradi, J., \& Zhu, H. (2013). A survey on bank branch efficiency and performance research with data envelopment analysis. Omega, 41, 61-79. 
Paradi, J. C., \& Schaffnit, C. (2004). Commercial branch performance evaluation and results communication in a Canadian bank - A DEA application. European Journal of Operational Research, 156, 719-735.

Paradi, J. C., Vela, S., \& Zhu, H. (2010). Adjusting for cultural differences, a new DEA model applied to a merged bank. Journal of Productivity Analysis, 33, 109-123.

Parkan, C. (1987). Measuring the efficiency of service operations: An application to bank branches. Engineering Costs and Production Economics, 12, 237-242.

Parkan, C., \& Wu, M. L. (1999). Measurement of the performance of an investment bank using the operational competitiveness rating procedure. Omega, 27, 201-217.

Pastor, J. M. (1995). Eficiencia, cambio productivo y cambio técnico en los bancos y cajas de ahorros españolas: Un análisis de la frontera no paramétrico. Revista Española de Economía, 12(1), 35-73.

Pastor, J. M., Pérez, F., \& Quesada, J. (1997). Efficiency analysis in banking firms: An international comparison. European Journal of Operational Research, 98(2), 395-407.

Pastor, J.T., Lovell, C. A. K, \& Tulkens, H. (2006). Evaluating the financial performance of bank branches. Annals of Operations Research, 145, 321-337. doi:10.1007/s10479-006-0038-3

Portela, M., \& Thanassoulis, E. (2007). Comparative efficiency analysis of Portuguese bank branches. European Journal of Operational Research, 177, 1275-1288.

Prior, D., Tortosa-Ausina, E., García-Alcober, M. P., \& Illueca, M. (2016). Costs, revenues and performance in Spanish banking: A comparative analysis of pre- and early crisis years. Spanish Journal of Finance and Accounting, 45(3), 345-364.

Respaut, B. (1989). Mesures de l'efficacité productive des 911 agences d'une banque privée Belge. In H. Tulkens (Ed..), Efficacité et Management .Chapter 3 (pp. 53-71). Charleroi, Belgium: CIFOP.

San-Jose, L., Retolaza, J. L., \& Pruñonosa, J. T. (2014). Efficiency in Spanish banking: A multistakeholder approach analysis. Journal of International Financial Markets, Institutions and Money, 32, 240-255.

Schaffnit, C., Rosen, D., \& Paradi, J. C. (1997). Best practice analysis of bank branches: An application of DEA in a large Canadian bank. European Journal of Operational Research, 98, 269-289.

Sherman, H. D., \& Gold, F. (1985). Bank branch operating efficiency: Evaluation with data envelopment analysis. Journal of Banking \& Finance, 9, 297-315.

Simar, L. (1996). Aspects of statistical analysis in DEA-type frontier models. Journal of Productivity Analysis, 7, 177-185.

Simar, L., \& Wilson, P. W. (2007). Estimation and inference in two stage, semi-parametric models of productive efficiency. Journal of Econometrics, 136, 31-64.

Tsolas, I. E., \& Giokas, D. I. (2012). Bank branch efficiency evaluation by means of least absolute deviations and DEA. Managerial Finance, 38(8), 768-785.

Tulkens, H. (1993). On FDH analysis: Some methodological issues and applications to retail banking, courts and urban transit. Journal of Productivity Analysis, 4(1-2), 183-210.

Tulkens, H., \& Malnero, A. (1996). Nonparametric approaches to the assessment of the relative efficiency of bank branches. In D. G. Mayes (Ed.), Sources of Productivity Growth. Chapter 10 (pp. 223-244). New York: Cambridge University Press.

Weill, L. (2004). Measuring cost efficiency in European banking: A comparison of frontier techniques. Journal of Productivity Analysis, 21(2), 133-152.

Worthington, A. (1999). Malmquist indices of productivity change in Australian financial services. Journal of International Financial Markets, Institutions and Money, 9(3), 303-320.

$\mathrm{Wu}$, D., Yang, Z., \& Liang, L. (2006). Efficiency analysis of cross-region bank branches using fuzzy data envelopment analysis. Applied Mathematics and Computation, 181, 271-281. 